\title{
Free-stretch-blow investigation of poly(ethylene terephthalate) over a large process window
}

\author{
James Nixon $^{1}$ (D) G. H. Menary ${ }^{1} \cdot$ S. Yan $^{1}$
}

Received: 27 May 2016/Accepted: 1 September 2016 / Published online: 26 September 2016

(C) The Author(s) 2016. This article is published with open access at Springerlink.com

\begin{abstract}
This paper highlights for the first time a full comprehension of the deformation procedure during the injection stretch blow moulding (ISBM) process of poly(ethylene terephthalate) (PET) containers, namely thin-walled rigid bottles. The processes required to form PET bottles are complicated and extensive; any development in understanding the nature of material deformation can potentially improve the bottle optimisation process. Removing the bottle mould and performing free-stretch-blow (FSB) experiments revealed insight into the bottle forming characteristics at various preform temperatures and blowing rates. Process outputs cavity pressure and stretch-rod force were recorded using at instrumented stretch-rod and preform surface strain mapping was determined using a combination of a unique patterning procedure and high speed stereoscopic digital image correlation. The unprecedented experimental analysis reveals that the deformation behaviour varies considerably with contrasting process input parameters. Investigation into the effect on deformation mode, strain rate and final bottle shape provide a basis for full understanding of the process optimisation and therefore how the process inputs may aid development of the preferred optimised container.
\end{abstract}

Keywords ISBM $\cdot$ PET $\cdot$ Free-stretch-blow $\cdot$ Digital image correlation

James Nixon

j.nixon@qub.ac.uk

1 School of Mechanical and Aerospace Engineering, Queen's University Belfast, Ashby Building, Stanmillis Road, Belfast BT9 $5 \mathrm{AH}$, Northern Ireland

\section{Introduction}

Poly (ethylene terephthalate) (PET) is the dominant material for the manufacture of thin-walled containers. This is due to its clarity, light weight, strength, recyclability and barrier properties, not to mention the relatively large process window available to the manufacturer [1]. The manufacturing process that has been developed to form the containers is the injection stretch blow moulding (ISBM) process; where injection moulded PET preforms are reheated above the glass transition temperature $\mathrm{Tg}$ using infrared radiation, placed into a suitable mould and then formed using a combination of linear stretching and air pressure inflation [2]. The pressure inflation occurs in two stages; pre-blow (6-10 bar) to form the majority of the bottle shape and final blow ( $>25$ bar) to form the final bottle shape and bottle details.

This manufacturing process is complex with variables such as magnitude of pressure, air flow, preform temperature and stretch-rod velocity all influencing the final bottle thickness and mechanical properties. As a result the process is a 'black art' and can rely heavily on previous knowledge and operator experience. This in turn can be costly in terms of raw material, mould material, energy and setup time. A more scientific approach into the effect of process conditions on PET bottles during the ISBM formation must be developed.

Determining the process outputs such as the evolving cavity preform cavity pressure $[3,4]$ and stretch-rod reaction force [1] from the ISBM experiment has been investigated over several years. Research has revealed that the cavity pressure within the developing preform is not taken as the supply line pressure, but in essence is a result of the air mass flow rate and cavity volume, which in turn is relatable to the preform material temperature. The material temperature also has a significant effect on the stretch-rod reaction force. Accurately 
measuring the preform temperature [5] and its effects on the blowing behaviour is critical for understanding the ISBM process.

Previous attempts have been made to examine the deformation behaviour of the preform within the mould. Cakmak et al. [6] investigated the kinematics of the bottle formation using linear variable differential transformer (LVDT) switches in the mould surface that were triggered on material contact. Inferring the bottle formation from contact switch activation relies heavily on the spacing of the switches and does not reveal the material deformation strains during bottle formation. Haung et al. [7] then developed a transparent mould made from poly (methyl methacrylate) while successfully recording the bottle shape development; measurement of the typical strain rates was not investigated. One way to further examine the bottle kinematics is to remove the mould and record the deformation. The free-stretch-blow (FSB) analysis is not a novel method of investigating the deformation behaviour from preform to bottle. Billon et al. [8] removed the mould to blow the preform in free air while recording the process with a high speed camera; details of the blowing process and bubble propagation were investigated as a function of process timing. The timing relationship between the stretchrod and the inflation initiation was found to heavily influence the free-blow bottle shape. Menary et al. [9] built upon the research by Billon through the application of a grid pattern to the outer preform surface and using the resultant displacement over time to reveal the evolving bottle to provide strain data. However, a more in-depth analysis of the evolving free-blown bottle shape proved necessary in an effort to attain more accurate values of strain levels and strain rate.

Digital image correlation (DIC) has been a proven analysis technique of acquiring non-contact, full field strain map of deforming surfaces. In its simplest 2D form [10-12], this involves a single camera recording the deformation at an appropriate frame rate. A speckled pattern applied to the subject surface is then tracked from each progressive image using correlation algorithms and the strain evolution is determined. This process has been used to great effect during the deformation of polymer specimens $[13,14]$ up to stretch ratios of 6.0 with accuracy in strain of $10^{-4}$. Critically these specimens are flat and orientated parallel to the CCD sensor of the camera; 2D DIC techniques are not suited for deformations with outof-plane displacements. When curved surfaces or when outof-plane displacements are evident, a 3D stereoscopic DIC analysis must be used [15]. 3D DIC uses two cameras focused onto the subject area orientated at a critical stereoscopic angle $\left(15-40^{\circ}\right)$; orientation of the cameras is then calibrated using specific calibration panels allowing the two cameras to relate themselves spatially [16]. The correlation analysis is then performed from each set of images from the two cameras to produce a three-dimensional map of the surface strain [17-19].
The goal of this research is to develop an accurate and reliable method of using the 3D DIC technique which can quantify the strain and strain rates associated with the ISBM process along with the cavity pressure evolution and stretch rod reaction force. Applying these analysis techniques over a large process window allows previously unidentified deformation phenomenon to be explored and produces data that is vital for developing mathematical models of the material behaviour and process.

\section{Experimental set-up}

At present, basic calculations based on the time to form a bottle and the corresponding maximum stretch ratio are used to give typical average strain rates for the process, approximately $30-50 / \mathrm{s}$ [9]. This paper will make use of 3D stereoscopic DIC to monitor the stain rates experienced during deformation over a large process window; encompassing material temperatures, supply pressures and flow rates typical of that used in industry.

All FSB trials were performed on a single cavity, lab scale stretch blow mould machine supplied by Vitalli \& Son [20] and located at Queen's University Belfast. The mould was removed and the preforms were simply clamped around the neck support finish allowing the bottle formation into free air. The stretch-rod was pneumatically actuated with an average velocity of $0.5 \mathrm{~m} / \mathrm{s}$. A stereoscopic analysis was employed for the FSB experiments utilising two Photron FASTCAM SA1.1 high speed cameras at a frame rate of up to 2000fps and lighting was provided by two $650 \mathrm{~W}$ halogen lamps, Fig. 1.

A critical aspect of the DIC procedure is the patterning technique used. Previous patterning techniques widely used for DIC involved the operator randomly spraying a contrasting speckle pattern (usually black on white) onto the subject surface $[21,22]$. This process was found to vary widely with each operator resulting in inconsistencies and struggled to maintain coherence to the end of the deformation, therefore resulting in patches of lost data. A more reliable and repeatable method of applying the pattern was then devised. This involved cutting a specific pattern from masking film using a CADCAM FB-700 laser cutter and applying a black speckle pattern onto a white base coat. Figure 2 shows the clarity and contrast of the pattern achieved before and after deformation. The spray paint used was Rust-oleum Universal All Surface matt black and matt white. It was confirmed that the paint on the preform surface had no effect on the mechanical properties of the PET by rotating the preform by $90^{\circ}$ and examining the high speed image stills to ensure deformation remained symmetrical, Fig. 3.

Table 1 displays the critical set-up geometry, optical values and correlation procedures for the stereoscopic DIC technique. 
Fig. 1 FSB experimental set-up

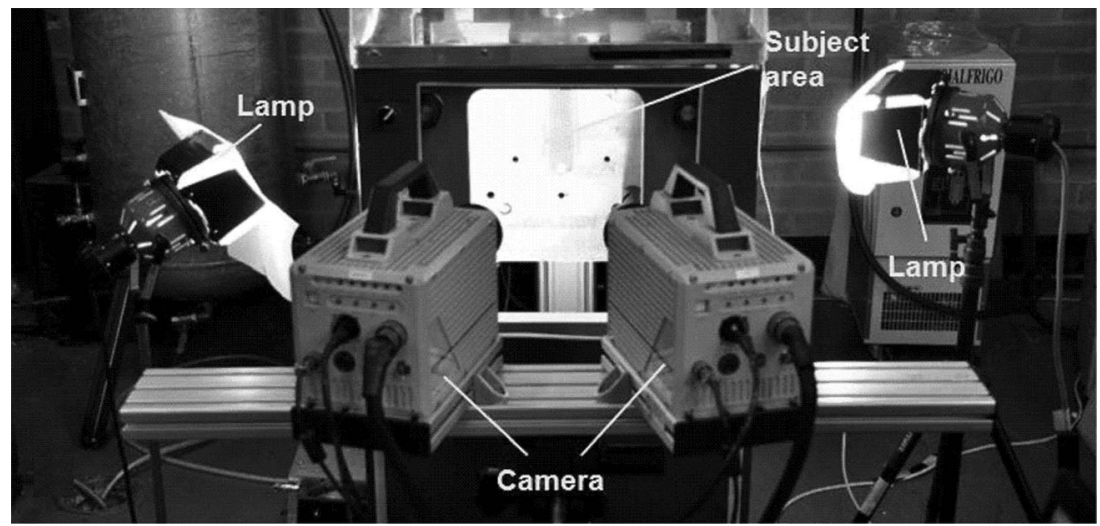

\section{Process data acquisition}

The cavity pressure evolution within the deforming bottle and the stretch-rod reaction force was recorded using an instrumented stretch rod, Fig. 4 [23]. The load cell and the pressure sensor, although miniature in size, were standard transducers based on the strain gauge principle. The sensitivity of the load cell and pressure sensor was $10 \mathrm{mV} / \mathrm{V}$ and $5.7 \mathrm{mV} / \mathrm{V}$ respectively. This corresponded to sensitivity in force and pressure of approximately $0.798 \mathrm{~N}$ and $1.313 \mathrm{kPa}$ respectively. The stretch-rod displacement was measured using a linear variable differential transformer (LVDT). The LVDT sensor used was an ACT6000C supplied by RDP Electronics with a sensitivity



Fig. 2 Speckle pattern comparison before and after deformation of $14.85 \mathrm{mV} / \mathrm{V} / \mathrm{mm}$. The sensors were then linked to a compactRIO data logger via an amplification module supplied by National Instruments.

\section{Design of Experiments}

The experimental trials were constructed to encompass a large process window for PET typical of the limits found in industry; accounting for material temperature $(\mathrm{T})$ and air flow rate (N). Although PET bottle production plants utilise an IR oven to reheat the preforms, the temperature profile form this heating method can vary extensively and is difficult to control. In an attempt to provide the preform temperature to a more controllable degree an alternate heating method was employed using a Grant GR-150 oil bath filled with silicone oil. With a resolution of $0.01{ }^{\circ} \mathrm{C}$ the patterned preform could be heated to a known value with full temperature equilibrium. Another aspect of potentially using an IR oven to heat the patterned preform was the onset of asymmetrical thermal crystallisation due to increased IR absorbance on the patterned side of the preform.

\section{Preform design \& material}

The preform used throughout the analysis was $31.7 \mathrm{~g}$ with a through diameter of $24.31 \mathrm{~mm}$ and a length of $97.16 \mathrm{~mm}$ (Fig. 5). The preforms were injected moulded using PET resin with an intrinsic viscosity of $0.81 \mathrm{dL} / \mathrm{g}$.

\section{Material temperature}

The glass transition temperature of the PET material was determined to be $79^{\circ} \mathrm{C}$ using differential scanning calorimetry. The oil bath set temperatures for the experimental trials therefore ranged from $95^{\circ} \mathrm{C}$ to $115^{\circ} \mathrm{C}$ with an increment of $5^{\circ} \mathrm{C}$; $90{ }^{\circ} \mathrm{C}$ was found to be too stiff for the preform to deform resulting in the stretch-rod punching through the preform tip 
Fig. 3 Symmetrical preform deformation

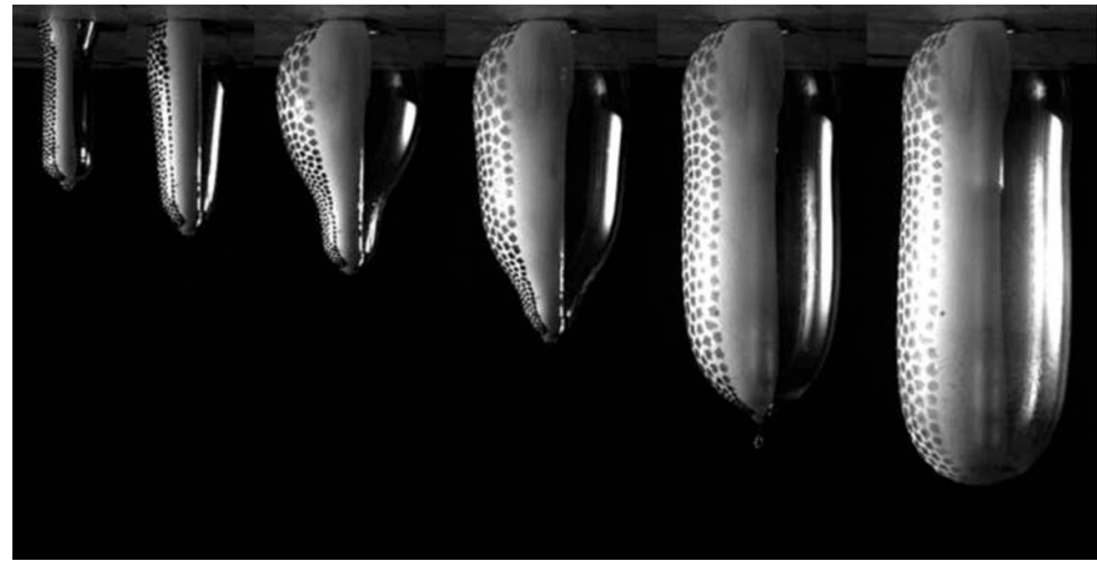

whilst temperatures greater than $115^{\circ} \mathrm{C}$ resulted in thermal crystallisation.

Heating times were applied to ensure full temperature equilibrium for the entire preform body (Fig. 5) which had a maximum wall thickness of $4.27 \mathrm{~mm}$. These were then verified using a simple heat transfer simulation using ABAQUS, employing axisymmetric solid elements (DCAX4). For the simulation, the heat transfer coefficient during heating was $461 \mathrm{~W} / \mathrm{m}^{2} \mathrm{~K}$ [24], determined by performing heating experiments and observing the preform temperature using a FLIR SC640 thermal camera with a spectral range of 7.5-13 $\mu \mathrm{m}$. The thermal conductivity and specific heat capacity for PET were taken from literature [25] where the values were a linear function of temperature (Table 2). The typical heating time to achieve temperature equilibrium through the preform thickness at $115^{\circ} \mathrm{C}$ was $2: 30 \mathrm{~min}$. A full review of the temperature loss due to transportation is detailed in future research [26].

Table 1 DIC set-up values

\begin{tabular}{ll}
\hline Technique used & Speckle pattern from masking \\
Pitch & $2 \mathrm{~mm}$ \\
Speckle size & $5-8$ pixels \\
Subset & $21 \times 21$ \\
Step size & 3 \\
Measurement points & 944 \\
Camera & 12 -bit $1024 \times 1024$ Photron FASTCAM SA1.1 \\
Field of view & $300 \times 300 \mathrm{~mm}$ (approx.) \\
Focal length & $600 \mathrm{~mm}$ (approx.) \\
Displacement & \\
$\quad$ Resolution & $1.875 \mu \mathrm{m}, 0.01$ pixels \\
Strain & \\
Correlation method & Incremental \\
Smoothing method & Gaussian filter, 15 \\
\hline
\end{tabular}

\section{Air flow rate}

For the purposes of the FSB trials the final blow pressure of 25 bar was disabled allowing analysis of pre-blow pressure only; the pre-blow pressure was fixed at 8 bar for these trials, a value commonly used in industrial applications. The air flow providing preform inflation for the SBM process is a combination of both supply pressure and adjustment of the flow restrictor. With the supply pressure fixed at 8 bar, a flow restrictor which had a range of zero (fully closed) to six (fully open) was used to control the flow rate of air. In this investigation three settings were used analysed; 2, 4 and 6 .

The timing relationship between the stretch-rod/preform contact and the pre-blow activation was maintained to be simultaneous, although in reality this may alter in industry between pre-blow advance (pressure activated before stretch$\mathrm{rod} /$ preform contact) and pre-blow delay (pressure activated after stretch-rod//preform contact)., depending on the preform/ bottle design.

Table 3 summarises the Design of Experiments. Assessing the repeatability of the complex free-blow process was attempted by examining the strain results from numerous repeats at the same process settings. Examining the strain plots and accounting for yield point, maximum strain rate and final strain (Fig. 6), a repeatability value of $5 \%$ was determined.

\section{Experimental post-processing}

\section{Correlation analysis}

The image correlation software used for the FSB trial was VIC3D, supplied by Correlated Solutions. The calibration routine was performed on a daily basis yielding a calibration error lower than $0.02 \mathrm{~mm}$. The calibration error is the overall error of the calibration set-up; the standard deviation of the 
Fig. 4 Instrumented stretch-rod

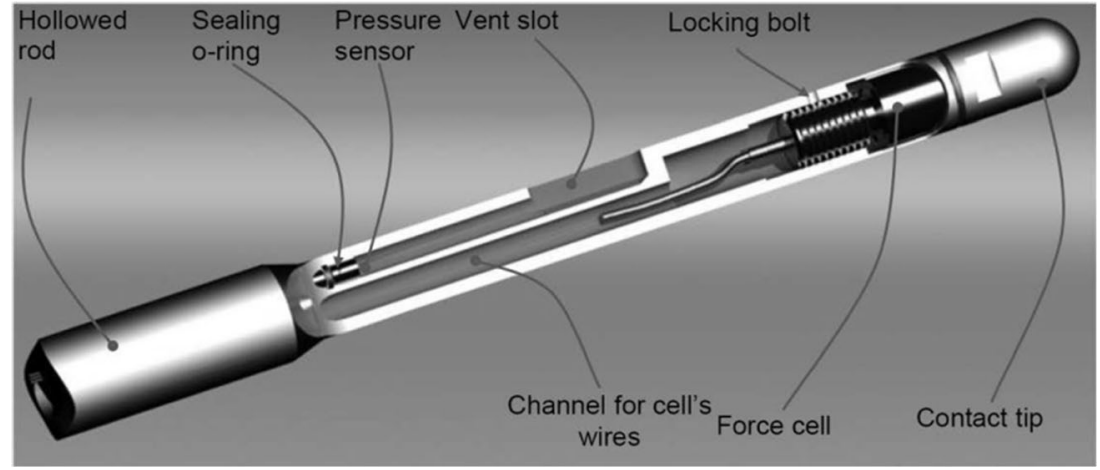

residuals for all the calibration images. A subset size of 29x29 pixels was used with correlation step size of 3. Fig. 7 displays a demonstration of the full field strain map attainable from the stereoscopic DIC experimental process.

\section{Experimental results}

The cavity pressure within the expanding preform, stretch-rod reaction force and surface strain results were captured; the outcome of which produced a 'fingerprint' plot for each of the trials. Fig. 8(a) displays the data produced from a preform blown at temperature $105^{\circ} \mathrm{C}$ and flow index 2 with the image still from the key frames shown in Fig. 8(b).

Time zero of the fingerprint indicates the simultaneous contact of the stretch-rod with the preform tip and the introduction of the air flow i.e. no pressure advance or delay. The trends of the fingerprint plot can be divided into five portions.

[1] $\mathbf{0}$ s to $0.125 \mathrm{~s}$ - uniaxial deformation of the preform. The linear cavity pressure rise indicates near isochoric flow conditions with preform deformation purely from stretch-rod displacement. This linear, uniaxial deformation is also apparent from the positive uniaxial strain and negative hoop strain. The high speed image at $0.125 \mathrm{~s}$ shows a preform that has purely stretch only with no pressure inflation.

[2] $\mathbf{0 . 1 2 5} \mathbf{s}$ to $\mathbf{0 . 2} \mathbf{s}$ - rapid preform inflation. The pressure drop indicates significant volume increase caused by the rapid inflation of the preform. This was reflected in the corresponding strain in both hoop and axial directions which begin to rise sharply. The stretch-rod force also drops in magnitude at a time of $0.175 \mathrm{~s}$ due to the pressure inflation attempting to blow the forming bottle off the stretch-rod tip. The image at $0.2 \mathrm{~s}$ shoes the preform after it has begun the bubble inflation process.

[3] $0.2 \mathrm{~s}$ to $0.35 \mathrm{~s}$ - continuous stretch-rod deformation with isobaric inflation. The stretch-rod continues to linearly deform the preform to the end of displacement at $0.35 \mathrm{~s}$. The steady air flow into the preform cavity and volume increase results in near-constant pressure output. This demonstrates the 'bubble' propagation from preform to bottle shape, as shown in the image at $0.35 \mathrm{~s}$.

Fig. 5 Preform design




Table 2 Thermal properties of PET required for heating simulation

\begin{tabular}{llll}
\hline $\begin{array}{l}\text { Material temperature } \\
\left({ }^{\circ} \mathrm{C}\right)\end{array}$ & $\begin{array}{l}\text { Thermal conductivity } \\
(\mathrm{W} / \mathrm{mK})\end{array}$ & $\begin{array}{l}\text { Specific heat capacity } \\
(\mathrm{J} / \mathrm{kgK})\end{array}$ & $\begin{array}{l}\text { Heat transfer coefficient } \\
(\text { cooling })\left(\mathrm{W} / \mathrm{m}^{2} \mathrm{~K}\right)\end{array}$ \\
\hline 90 & 0.160 & 1601.40 & 9.42 \\
115 & 0.143 & 1677.13 & 12.99 \\
\hline
\end{tabular}

[4] $0.35 \mathrm{~s}$ to $0.55 \mathrm{~s}$ - continuous pressure inflation relaxing off stretch-rod. The air flow continues to enter the preform resulting in steady pressure increase. The pressure increase indicates that the rate of volume increase reduces, suggesting the material enters the strain hardening phase. This is demonstrated in the image at $0.55 \mathrm{~s}$ where the bottle continues to form into a long 'sausage' like shape.

[5] $\mathbf{0 . 5 5} \mathrm{s}$ to end - pressure inflation leaving stretch-rod. The pressure continues to increase towards the 8 bar supply pressure, then the material leaving the stretch-rod tip at $0.55 \mathrm{~s}$. After the FSB bottle formation the pressure was removed and the experiment ended. The high speed image at $1.0 \mathrm{~s}$ displays a bottle shape that steadily grows with pressure increase.

The cavity pressure, stretch-rod force and surface strain data was obtained for a series of experiments encompassing the process parameters oil set temperature and flow index (air flow rate) with the supply pressure fixed at 8 bar. The key points from the data gathered were then compared as a function of the process parameters.

\section{Results and discussion}

\section{Peak cavity pressure}

The peak pressure after the initial linear pressure gradient was recorded for each trial, Fig. 9 i.e. point A Fig. 8(a).

The peak pressure for the three flow indices follow the same trends and reduces as the preform temperature increases. With increasing temperature, the material becomes more

Table 3 Design of experiments with labels

\begin{tabular}{llll}
\hline Temperature $\left({ }^{\circ} \mathrm{C}\right)$ & \multicolumn{2}{l}{ Flow index } & \\
\cline { 2 - 4 } & 2 & 4 & 6 \\
\hline 95 & N2 T95 & N4 T95 & N6 T95 \\
100 & N2 T100 & N4 T100 & N6 T100 \\
105 & N2 T105 & N4 T105 & N6 T105 \\
110 & N2 T110 & N4 T110 & N6 T110 \\
115 & N2 T115 & N4 T115 & N6 T115 \\
\hline
\end{tabular}

readily deformable and the cavity volume expansion rate increases; cavity volume is inversely proportional to cavity pressure at steady flow rates. Interestingly the peak pressure values for flow index 4 and 6 were very similar with a large difference occurring for flow index 2 indicating that the difference in flow rate was minimal. The reason for this was the relative difference in air flow rate at flow index settings 2,4 and 6 . The linear increase in flow index setting did not result in a linear increase in flow rate. An in-depth study of the air flow rate will be detailed in future research [26]. The maximum pressure observed for flow index setting 2 and oil temperature $95{ }^{\circ} \mathrm{C}$ was $0.79 \mathrm{MPa}$ i.e. the line pressure setting $(0.8 \mathrm{MPa})$. The maximum pressure observed for flow indices 4 and 6 for the same oil temperature was $0.84 \mathrm{MPa}$ and $0.85 \mathrm{MPa}$ respectively i.e. greater than the line pressure. This may initially seem an irregularity that was detrimental to the experiment, however it was clear that there was a certain amount of pressure 'surge', or shockwave as the high flow rate air initially entered the preform cavity. The shockwave was only observed during the high flow setting and low preform temperature trials where the preform had a larger resistance to deformation. Although not detrimental to the overall process, it does indicate how complex the pressure inflation actually is and specifying the line pressure only tells part of the story. It must be reiterated that cavity pressure only reveals an indication to the volume change over time, not the shape profile; this must be investigated using the strain analysis.

\section{Initial preform stiffness}

A characteristic that can be extracted from the force plots is the initial linear force gradient that occurred before the preform

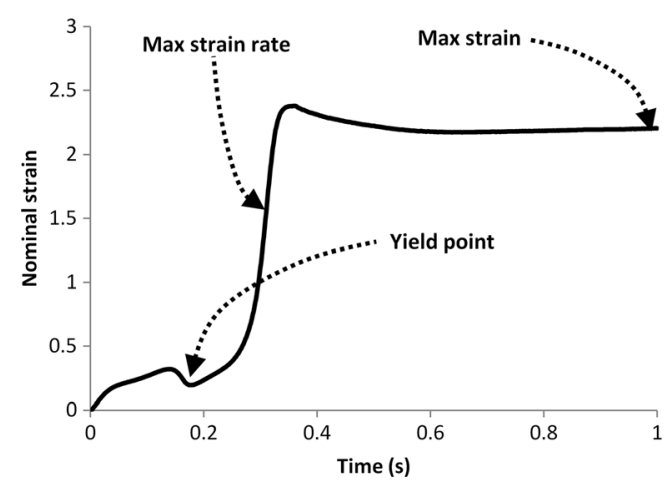

Fig. 6 Critical strain data to determine experiment repeatability 

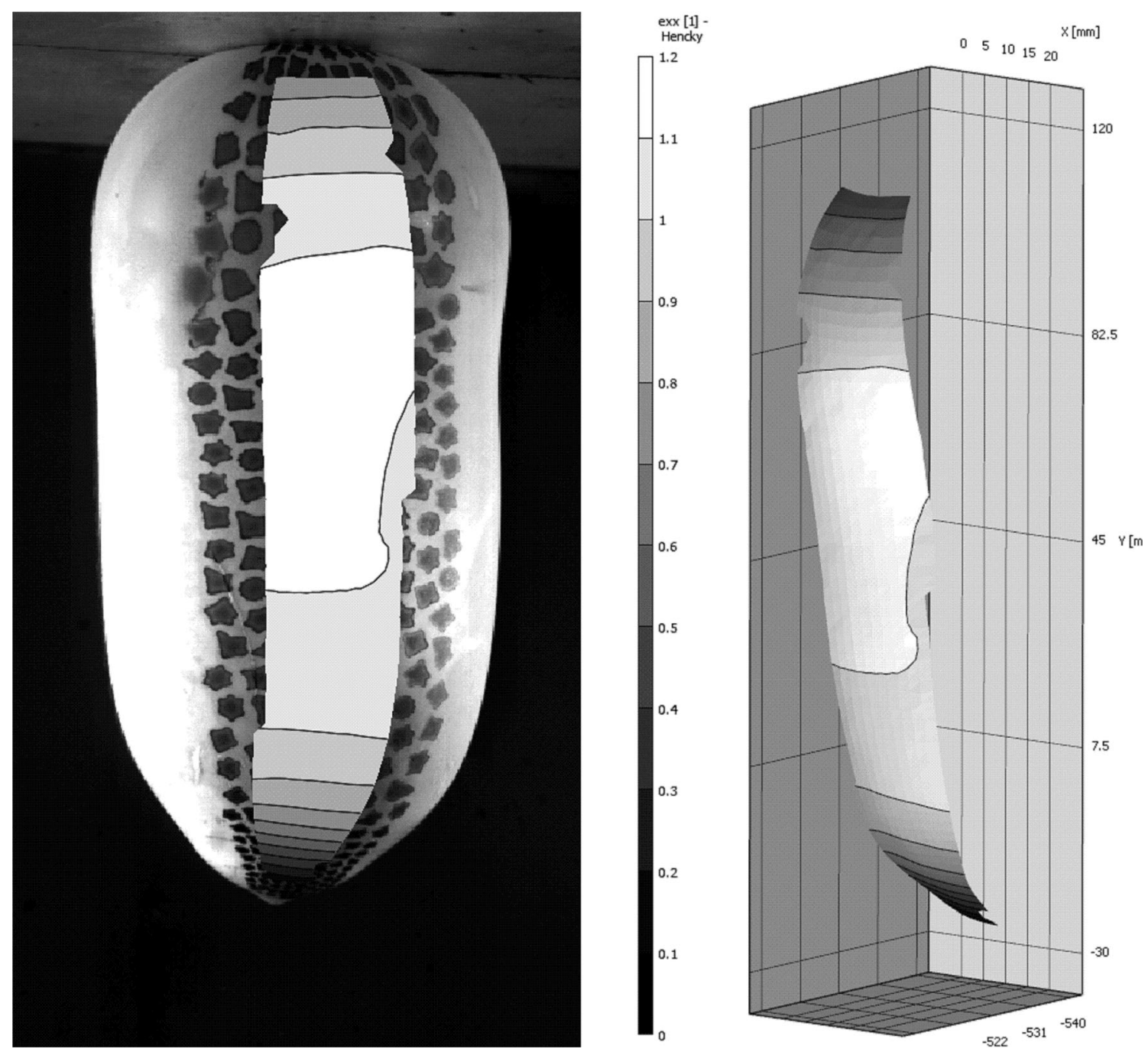

Fig. 7 Typical full field strain map, 2D and 3D representation (hoop strain displayed)

inflation became prominent. This can be evaluated as the initial preform stiffness by dividing by the stretch-rod velocity, Fig. 10.

Stiffness, $k(\mathrm{~N} / \mathrm{mm})=\frac{\text { Force gradient }(\mathrm{N} / \mathrm{s})}{\text { Stretch-rod velocity }(\mathrm{mm} / \mathrm{s})}$

As was to be expected the flow rate did not greatly affect the initial preform stiffness; the maximum standard deviation between the three flow indices was $5.69 \mathrm{~N} / \mathrm{mm}$ at an oil temperature of $95{ }^{\circ} \mathrm{C}$ where the average stiffness was $98 \mathrm{~N} / \mathrm{mm}$. As expected the temperature of the preform did significantly affect the stiffness, reducing with increased temperature. The stiffness remained relatively unchanged at an oil temperature of $110^{\circ} \mathrm{C}$ and above, levelling out at approximately $17 \mathrm{~N} / \mathrm{mm}$. The large drop in material stiffness from $95^{\circ} \mathrm{C}$ to $100^{\circ} \mathrm{C}$ of $70 \%$ can be attributed to the higher elastic modulus at lower material temperatures. The step increase in stiffness when temperature decreased from $100{ }^{\circ} \mathrm{C}$ to $95{ }^{\circ} \mathrm{C}$ was a result of the material temperature approaching the material $\mathrm{Tg}$, where the material begins to transition from the rubbery phase back to the glassy phase therefore significantly increasing the modulus and reducing deformability.

\section{Stretch-rod peak reaction force}

The peak reaction force between the stretch-rod and preform contact observed at the end of the stretching phase was plotted relative to oil temperature setting and flow index, Fig. 11 i.e. point B Fig. 8(a).

As with the pressure peak magnitude (Fig. 9), the peak force magnitude reduced as the material temperature increased; the largest reaction force of $762 \mathrm{~N}$ occurring for trial N2 T95 and lowest force $87 \mathrm{~N}$ for trial N4 T115. The increased flow index also reduced the peak force magnitude to the point where the highest flow index 6 revealed no end peak force for the higher oil temperatures i.e. the deforming preform prematurely left the stretch-rod tip before the end of stretch-rod motion. The reduced stretch-rod force from increased temperature and flow rate is a 
Fig. 8 a 'Fingerprint' plot for FSB trial; flow index 2, material temperature $105^{\circ} \mathrm{C}(\mathrm{N} 2 \mathrm{~T} 105)$ and $\mathbf{b}$ preform to bottle shape from key time frames (a)

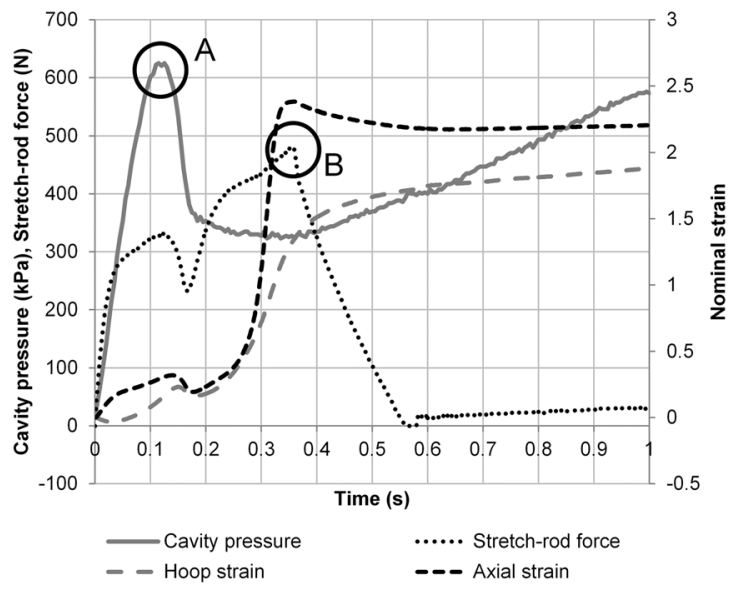

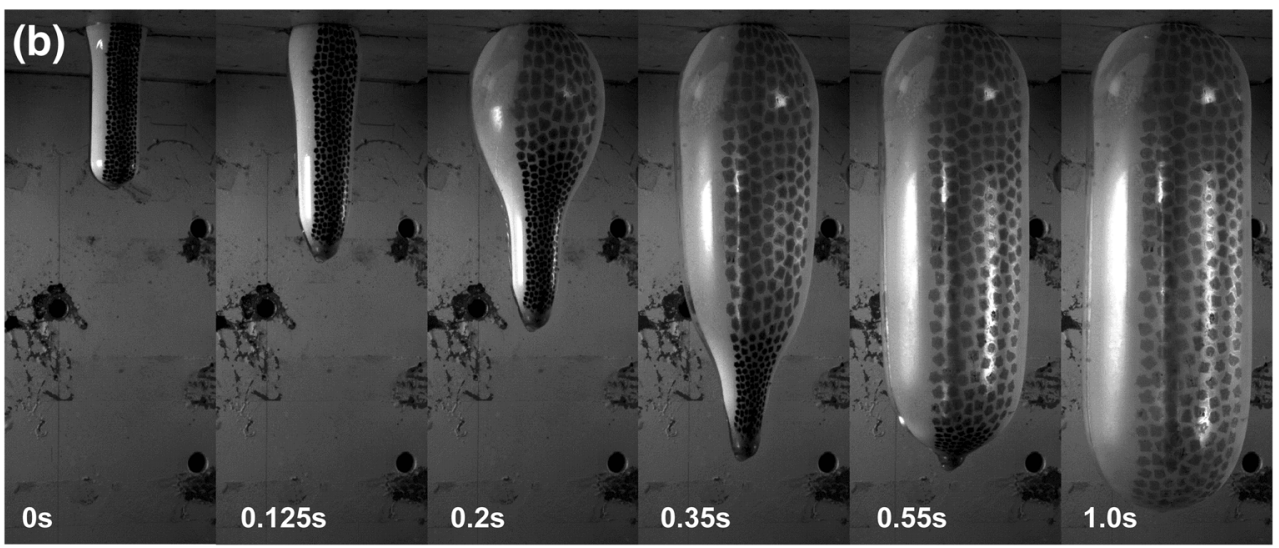

combination of the increased material deformability and the deformation becoming more reliant on pressure inflation i.e. the stretch-rod becomes less significant during the deformation process. The preform prematurely leaving the stretch-rod tip is undesired in the ISBM process as consistent stretch-rod contact centralises the deformation relative to the mould and reduces wall thickness variation. This can be resolved by certain process alterations; reducing the flow rate, increasing the stretch-rod

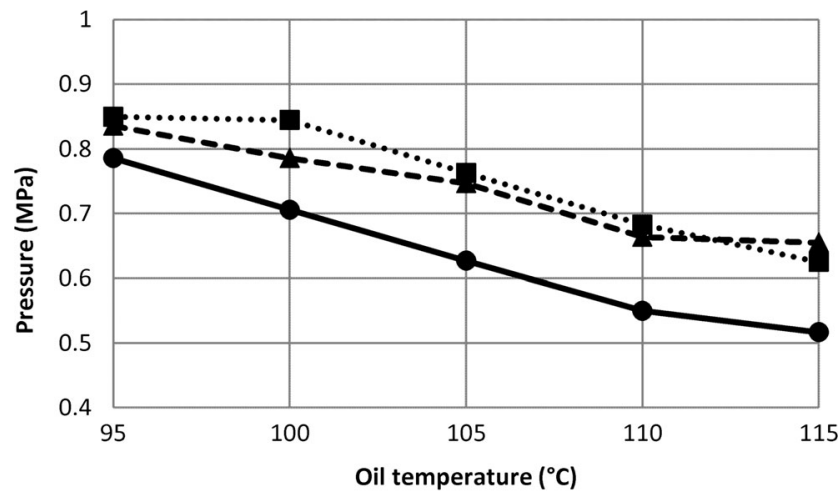

-Flow index 2 - $\mathbf{A}$ - Flow index 4 .

Flow index 6

Fig. 9 Peak cavity pressure for each flow index, relative to temperature velocity or increasing the pre-blow delay i.e. the delay time from stretch-rod contact to pre-blow pressure activation. The stretchrod velocity was relatively slow for these experiments at $0.5 \mathrm{~m} / \mathrm{s}$ where in industry the velocity can reach $2.0 \mathrm{~m} / \mathrm{s}$ Therefore at higher flow rates the preform can be expected to prematurely leave the stretch-rod tip during these experimental trials.



Flow index 2 -

Fig. 10 Initial preform stiffness for each flow index, relative to oil temperature 




Fig. 11 Peak force magnitude for each flow index, relative to oil temperature

\section{Surface strain}

Although a full field strain map was obtainable for the FSB trials, single data points were available to extract the strain evolution at different locations over the preform surface. Figure 12 shows the hoop and axial nominal strain from trial N2 T105 for three points on the preform; (1) $20 \mathrm{~mm}$, (2)
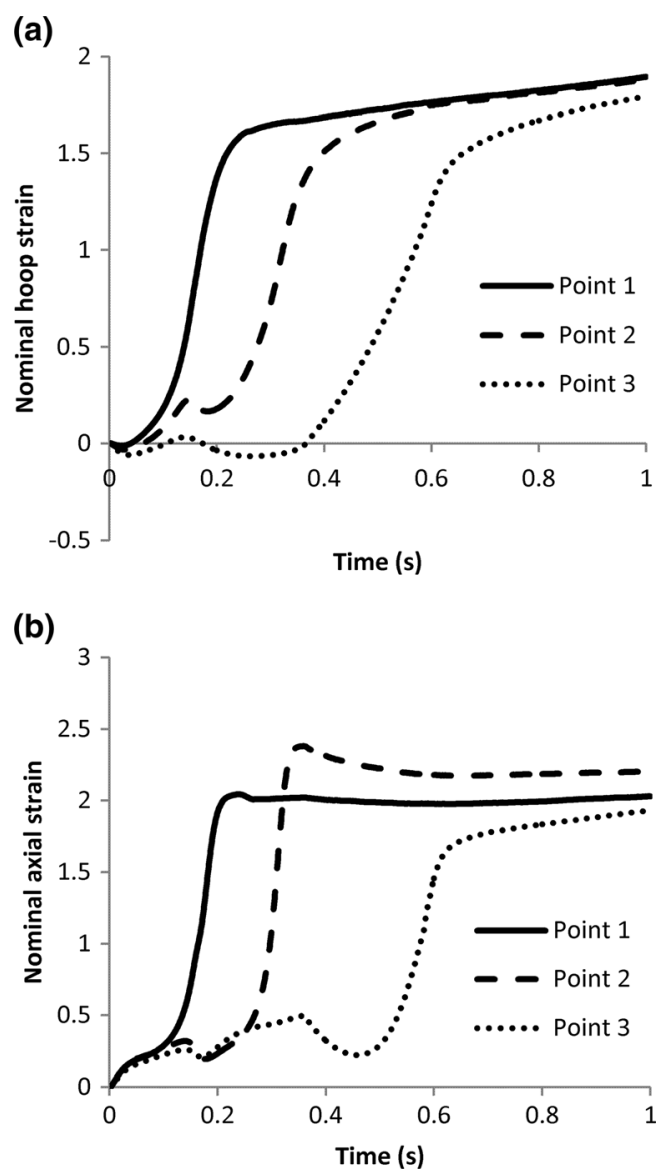

Fig. 12 a hoop and $\mathbf{b}$ axial nominal strain evolution from different preform locations
$43 \mathrm{~mm}$ and (3) $66 \mathrm{~mm}$ from the neck support ring. The data point chosen for the strain analysis was point 2 as it was the midpoint along the parallel section of the preform sidewall.

The strain results from Fig. 12 demonstrates the complexity of the preform deformation with multiple variations of yield point, strain rate and final strain depending on the location on the preform.

\section{Preform yield point}

This was regarded as the point in time when the preform yielded and the strain rapidly increased, Fig. 6. The time to yield taken from the strain curves was then plotted for each flow index relative to oil temperature, Fig. 13.

The trends from Fig. 13 indicate that as the oil temperature increased, the preform yielded more readily. The time point for yield also reduced as the flow index was increased, with the low flow rate setting taking a minimum time of $160 \mathrm{~ms}$ to yield and the high flow setting taking $70 \mathrm{~ms}$. Similar to the pressure and stretch-rod force trends, there was little difference observed between the flow index setting of 4 and 6. As previously mentioned, this was due to the non-linear flow rate response as a function of flow index setting. The point at which the preform yields to begin rapid expansion has a significant bearing on the nature of the deformation behaviour i.e. early preform yield may lead to rapid inflation resulting in the preform being blown off the end of the stretch-rod; contrary to this, delayed yield will result in a sequential-biaxial deformation when the deformation is initially performed by the stretch-rod and subsequently stretched by the inflation air. The timing of the pre-blow pressure activation relative to the stretch-rod motion provides control of the desired sequential deformation mode without the preform prematurely leaving the stretch-rod. The yield point can have a significant influence on how the preform deforms and as a result the properties of the final bottle. An early yield may result in early bubble



-Flow index 2 - 1 - Flow index 4 ․․․ Flow index 6

Fig. 13 Preform yield point from strain results 
formation producing a 'top heavy' bottle, while late yield may result in a stretch-rod dominated deformation producing a 'bottom heavy' bottle.

\section{Strain rate}

Accurate strain rate levels were also attainable from the DIC technique. Result revealed that increased temperature and flow rate increased the potential strain rate i.e. deformation rate. Strain rate is an important factor when assessing PET for the use in thin-walled containers; a wealth of previous research has revealed that increased strain rate improves the mechanical properties of the final bottle. The DIC routine used here demonstrates how strain rate is now a reliable process output that can be accurately obtained and optimised.

Both the hoop and axial strain experienced an increase in rate as the bubble propagated and biaxial deformation became prominent i.e. the maximum strain observed in the fingerprint plot, Fig. 8(a). Figure 14 shows the trends in the maximum strain rate in hoop and axial directions for each flow index while varying the oil temperature.

As the temperature increased, the strain rate in both the hoop and the axial direction increased, albeit in a different manner. The hoop strain for the three flow indices (Fig. 14 (a)) increased with temperature, the rate of increase differed significantly as the flow rate increased; the maximum strain rate was $15.97 / \mathrm{s}, 32.76 / \mathrm{s}$ and $37.35 / \mathrm{s}$ for flow index N2, N4 and N6 respectively. The maximum hoop strain rate for flow index 6 was $134 \%$ greater than for flow index 2 indicating that the flow rate had a significant bearing on the rate of inflation in the hoop direction. Contrary to hoop strain, the axial strain rate for the three flow indices (Fig. 14 (b) increased together by the same proportion, with no particular difference as the flow rate increased; the maximum strain rate was $63.05 / \mathrm{s}, 62.35 / \mathrm{s}$ and $76.67 / \mathrm{s}$ for flow index N2, N4 and N6 respectively. The maximum axial strain rate for flow index 6 was $22 \%$ greater than for flow index 2. It is important to note that the point at which maximum axial strain rate occurs was during the rapid pressure inflation, irrespective of stretch-rod speed. Critically the material characterisation technique employed by QUB [27, 28] utilising a biaxial stretching machine had a maximum test strain rate of only $32 / \mathrm{s}$; clearly the strain rates observed during the FSB trials exceed this strain rate limit and the biaxial testing procedures are therefore not equivalent to that of true PET bottle production. This may have a detrimental effect on the material characterisation routine used to produce supposedly reliable and robust material models implemented for FE simulations.

The magnitude of the axial strain rate was significantly greater than the hoop strain rate. It was also possible to plot the strain rate (a)

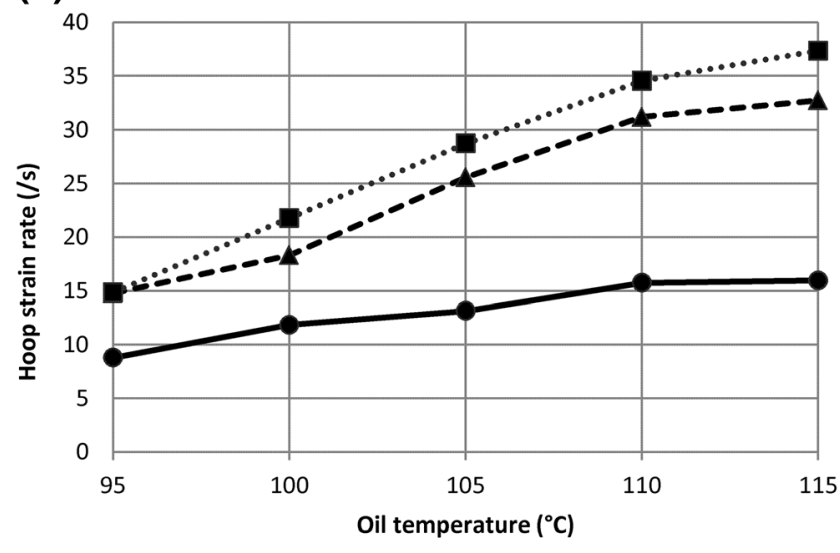

Flow index $2 \quad \ldots-$ - Flow index $4 \quad \ldots$. Flow index 6

(b)



Flow index 2 - $\mathbf{A}$ - Flow index 4 ... Flow index 6

Fig. 14 Maximum strain rate for each flow index while varying oil temperature; $\mathbf{a}$ hoop strain and $\mathbf{b}$ axial strain

ratio as an indication of the deformation mode, Fig. 15; a strain rate ratio of 1 would indicate an equal biaxial deformation,

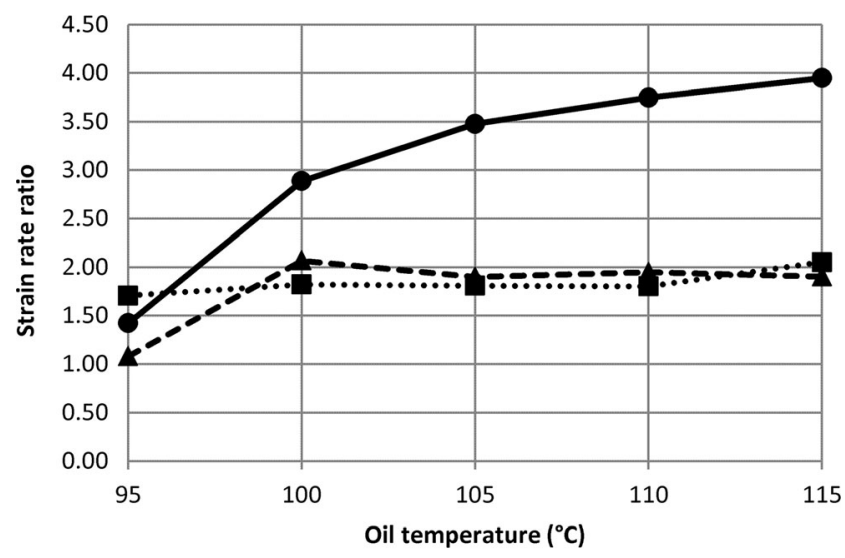

Flow index 2 - Flow index 4 . Fl. Flow index 6

Fig. 15 Maximum strain rate ratio as a function of oil temperature for three flow indices 
greater than 1 would be biased in the axial direction and below 1 would be biased in the hoop direction.

$\varepsilon_{\text {Ratio }}=\frac{\varepsilon_{\text {axial }}}{\varepsilon_{\text {hoop }}}$

All FSB trials demonstrated unequal biaxial deformation bias in the axial direction. It is important to note that the time location of the maximum axial strain rate was located when the bubble rapidly propagated from preform to bottle shape; it was not strictly relative to the stretch-rod motion. This is not to say that the stretch-rod deformation had no effect on the strain rate ratio. The low flow rate trials where the stretch-rod deformation had a relatively greater effect revealed a strain rate ratio increased steadily with oil temperature to maximum of 3.95 . Contrary to this, the high flow rate trials with a more pressure influenced deformation remained relatively constant with respect to material temperature with an average strain rate ratio of 2.07. The influence of the stretch-rod on the preform deformation clearly reduces for the higher flow rate trials.

\section{Aspect ratio}

The strain ratio provides an insight into the ratio of strain localised to point 2 on the preform surface. Although this allows some indication to the bottle shape, the true bottle shape was also measured from the image stills of the deformed bottle at the end of the FSB trials. The aspect ratio was considered the ratio between the vertical length and diameter of the bottle before the pressure was released. The aspect ratio was then determined for each trial, Fig. 16.

Aspect ratio $=\frac{l}{\varnothing}=\frac{\text { Vertical length }}{\text { Diameter }}$

The bottle length and diameter were measured using the still images from the FSB experiments. The length was

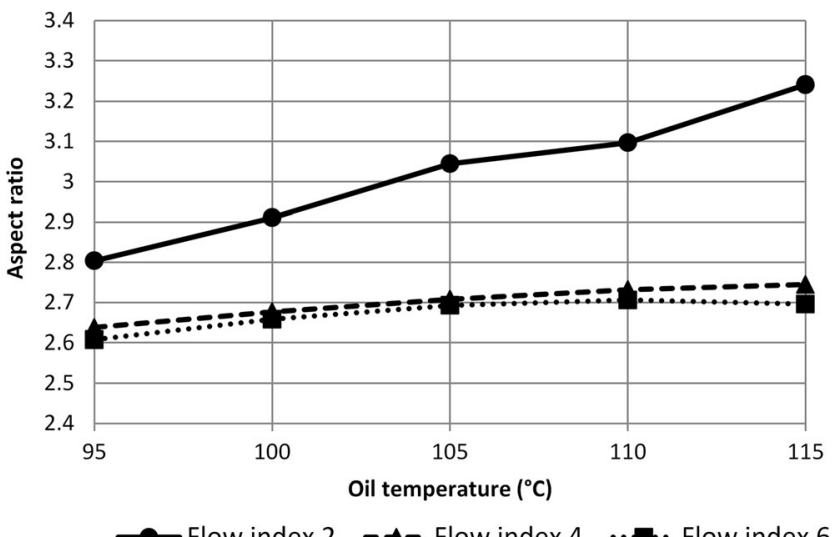

Fig. 16 Aspect ratio for the final FSB bottle shape relative to flow index and oil temperature measured from the neck support ring to the bottle base and the diameter was measured at the location of the strain extraction point i.e. the point on the preform surface $43 \mathrm{~mm}$ from the neck support ring. Examining the aspect ratios for the trials a clear trend was apparent where the low flow index 2 trials produced a higher aspect ratio than the higher flow indices for the entire temperature range; this revealed a more slender bottle shape with an average increase in aspect ratio of 0.35 over the temperature range. During the flow index 2 trials, the aspect ratio steadily increased as a function of temperature from 2.8 to a peak of 3.28; as the temperature increased, the bottle formed became more and more elongated after it eventually separated from the stretch-rod tip. This was also apparent for certain high flow index trials where the stretch-rod was in contact for the majority of the blowing phase. At $110^{\circ} \mathrm{C}$ and above when the deformation was almost purely free-blow (premature blow-off from stretch-rod tip) the aspect ratio did not increase significantly, indicating a relatively fatter bottle compared to the lower temperatures. Examining the images from the high speed FSB trials and comparing the contrasting low aspect ratio (N6 T95) and high aspect ratio (N2 T115) reveals the significance in resultant bottle shape, Fig. 17. When reverting to an industrial application where the mould is applied and a specific bottle is designed for the desired preform, the aspect ratio is a critical factor in dictating the

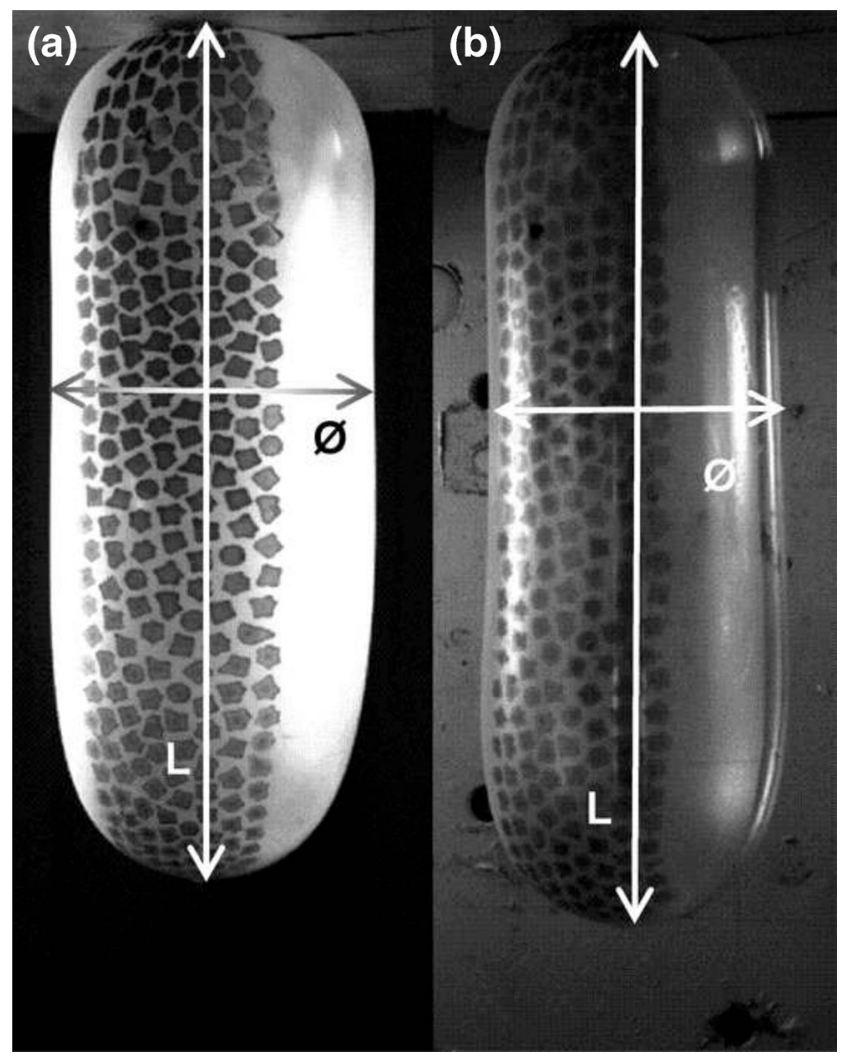

Fig. 17 Contrasting aspect ratio comparison; a low aspect ratio (N6 T95) and $\mathbf{b}$ high aspect ratio (N2 T115) 
eventual bottle shape; this examination reveals that material temperature and air flow rate are key parameters to optimise the final bottle design.

The knowledge gained from these analyses allow for greater insight into the nature of preform deformation during the ISBM process and how input parameters such as material temperature and air flow rate are critical in understanding how a bottle is formed, how the process may be optimised and, most importantly, how the formation process may be altered to produce an optimised final bottle. The information gathered also allows for the future development and validation of the FE simulation for the ISBM process, another tool that can benefit the investigation and optimisation of PET bottle formation.

\section{Conclusions}

A novel experimental method has been developed using a stereoscopic DIC technique to attain the full field strain map of deforming bottle during the free stretch blow process. Along with internal cavity pressure and stretch-rod reaction force, a complete depiction of the preform deformation was captured over a large process window encompassing material temperature and air flow rate.

Experimental trials revealed that a reduction in flow index reduced the effective deformation due to pressure inflation with a decrease in air flow rate. Pressure magnitudes were also decreased as the material temperature increased highlighting the increase in preform deformability. Stretch-rod force magnitudes decreased with increased material temperature due to increased deformability. Increasing the flow index also decreased the force magnitude due to dominant pressure inflation, resulting in the preform even prematurely blowing off the preform tip. Predictably, initial preform stiffness significantly reduced as material temperature increased with insignificant affect from altering the flow index.

Strain rates observed during the FSB process approached values of $80 / \mathrm{s}$, regularly exceeding the maximum strain rate achievable for the biaxial material testing machine at QUB of 32/s. This will in-turn effect the characterisation process used to produce the material model for the simulation. It was also found that material temperature is more influential on the rate of deformation than the final strain values.

Bottle shape and aspect ratio are highly dependent on the proportion of stretch-rod deformation relative to pressure inflation; dominated by stretch-rod deformation results in a more slender bottle shape whilst pressure domination results in a fatter bottle. This influences the material distribution and performance for the final production bottle.
The large data set produced from these experiments is now available to correlate against corresponding simulations and assess the accuracy.

\section{Compliance with ethical standards}

\section{Conflict of interest None}

Open Access This article is distributed under the terms of the Creative Commons Attribution 4.0 International License (http:// creativecommons.org/licenses/by/4.0/), which permits unrestricted use, distribution, and reproduction in any medium, provided you give appropriate credit to the original author(s) and the source, provide a link to the Creative Commons license, and indicate if changes were made.

\section{References}

1. F M Schmidt, J F Agassant, and M Bellet, Experimental study and numerical simulation of the injection stretch/blow moulding process, Polym Eng Sci 38(9), pp. 1399-1412, Sept 1998.

2. Yang ZJ, Harkin-Jones EM, Armstrong CG, Menary GH (2004) Finite element modelling of stretch-blow moulding of PET bottles using Buckley model: plant tests and effects of process conditions and material parameters. J Process Mech Eng 218(4):237-250

3. Borrdival M, Schmidt FM, Le Maoult Y, Coment E (2007) Measurement of thermal contact resistance between the mould and the polymer for the stretch blow moulding process. In ESAFORM, Zaragoza

4. Haessly WP, Ryan ME (1993) Experimental study and finite element analysis of the injection blow moulding process. Polym Eng Sci 33(19):1279-1287

5. Bordival M, Schmidt FM, Le Maoult Y, Velay V (2009) Optimisation of preform temperature distribution for the stretchblow moulding of PET bottles: Infrared heating and blowing modelling. Polym Eng Sci 49(4):783-793

6. Cakmak M, White JL, Spruiell JE (1985) An investigation of the kinematics of stretch blow moulding poly (ethylene terephthalate) bottles. J Appl Polym Sci 30(9):3679-3695

7. Haung HX, Yin ZS, Liu JH (2007) Visualisation study and analysis of preform growth in polyethylene terephthalate stretch blow moulding. J Appl Polym Sci 103(1):564-573

8. Billon N, Erner A, Gorlier E (2005) Kinematics of stretch blow moulding and plug assisted thermoforming of polymers; experimental study. In 21st Annual Meeting of the Polymer Processing Society- PPS, Leipzig, Germany, 19-23 June 2005

9. Menary GH et al. (2010) Validating Injection Stretch Blow Moulding Simulation via Free Blow Trials. Polym Eng Sci 50(5): 1047-1057

10. Lecompte D et al. (2006) Quality assessment of speckle patterns for digital image correlation. Opt Lasers Eng 44(11):1132-1145

11. Yoneyama S, Ueda H (2012) Bridge deflection measurement using digial image correaltion. Mater Trans 53(2):285-290

12. Tao G, Xia Z (2005) A non-contact real-time strain measurement and control system for multiaxial cyclic/fatigue tests of polymer materials by digital image correlation method. Polym Test 24(7): 844-855

13. Parsons E, Boyce MC, Parks DM (2004.) An experimental investigation of the large-strain tensile behavior of neat and rubbertoughened polycarbonate. Polymer 45(8):2665-2684 
14. Chevalier L, Calloch S, Hild F, Marco Y (2001) Digital image correlation used to analyze the multiaxial behavior of rubber-like materials. Eur J Mech 20(2):169-187

15. Sutton MA, Yan JH, Tiwari V, Schreier HW, Orteu JJ (2008) The effect of out-of-plane motion on 2D and 3D digital image correlation measurements. Opt Lasers Eng 46(10):746-757

16. Sutton MA, Orteu J-J, Schreier HW (2009) Image correlation for shape, motion and deformation Measurments. Springer, New York

17. van Mieghem B, Lava P, Debruyne D, van Bael A, Ivens J (2013) Digital image correlation for on-line wall thickness measurements in thick gauge thermoforming. In Key Engineering Materials, Aveiro

18. Grytten F, Daiyan H, Polanco-Loria M, Dumoulin S (2009) Use of digital image correlation to measure large-strain tensile properties of ductile thermoplastics. Polym Test 28(6):653-660

19. Tiwari V et al. (2009) Application of 3D image correlation for fullfield transient plate deformation measurements during blast loading. Int J Impact Eng 36(6):862-874

20. Vitalli \& Son. [Online]. http://vitaliiandson.eu/

21. Crammond G, Boyd SW, Dulieu-Barton JM (2013) Speckle pattern quality assessment for digital image correlation. Opt Lasers Eng 51(12):1368-1378
22. Hua T et al. (2011) Evaluation of the quality of a speckle pattern in the digital image correlation method by mean subset flucuation. Opt Laser Technol 43(1):9-13

23. Salomeia Y, Menary GH, CG A (2008) Instrumentation of the stretch blow moulding process. In Polymer Processing Society, Salerno

24. Nixon J (2015) Analysis of the Stretch Blow Moulding Process and Subsequent Simulation Development. Queen's University Belfast

25. Lopez CM, Felisberti MI (2004) Thermal conductivity of PET/ (LDPE/AI) composites determined by MDSC. Polym Test 23(6): 637-645

26. Nixon J, Menary GH, Yan S Finite element simulations of stretchblow moulding with experimental validation over a broad process window. UNDER REVIEW

27. Menary GH, Tan CW, Armstrong CG (2012) The effect of temperature, strain rate and strain on the induced mechanical properties of Biaxially stretched PET. Key Eng Mater 1117: 504-506

28. Menary GH, Tan CW, Harkin-Jones EM, Armstrong CG, Martin PJ (2011) Biaxial deformation and experimental study of PET at conditions applicable to stretch blow molding. Polym Eng Sci 52(3):671-688 